\title{
Surgical repair of straddling and overriding tricuspid valve
}

\author{
Robert H. Anderson
}

$\mathrm{I}$

N THE ACCOMPANYING ARTICLE, ${ }^{1}$ REDDY AND his colleagues describe an important advance in the treatment of patients with straddling tricuspid valve - namely a reversion towards achieving biventricular repair. This approach of striving to incorporate both ventricles in separate circulations, described some time ago by Pacifico and his colleagues, ${ }^{2}$ has tended to be superseded more recently by the technically less-demanding Fontan surgical route, although an extensive series of biventricular repairs has been described very recently by Serraf and his colleagues from Paris. ${ }^{3}$ Both Reddy et al and Serraf and colleagues ${ }^{3}$ achieve excellent results, matching the very best offered from the univentricular option. The cost paid in the series reported by Reddy and his associates, ${ }^{1}$ also found in the initial report of Pacifico et $a l^{2}$ was a high incidence of surgically induced complete heart block. This latter complication is worrisome but, in my opinion, can be avoided when the anatomy of the straddling valve and its accompanying ventricular communication is properly understood.

There lies the rub. The anatomy of hearts complicated by straddling and overriding of the tricuspid valve remains a contentious issue. Serraf and his colleagues ${ }^{3}$ argued that, because they avoided heart block by placing their stitches on the left side of the septal crest, the anatomy of the conduction axis "follows the same descriptive features as in hearts with a VSD but without straddling". This statement was substantiated only by their strong belief, and no supporting anatomic evidence was provided. In fact, the morphologic evidence which exists contends strongly against their hypothesis. The excellence of their surgical results, and the success of their technique of using fine endocardial sutures in avoiding heart block, cannot disguise the fact that the anatomic arrangement of hearts with straddling and overriding of the tricuspid valve is fundamentally different from those with a ventricular septal defect in which the tricuspid valve is tethered exclusively within the right ventricle. ${ }^{4}$
Further problems are raised in anatomic terms when the structure of the heart containing a straddling tricuspid valve is compared to "atrioventricular canal malformations", 5,6 since this also colours thinking about the atrioventricular conduction axis. The debate upon whether or not straddling tricuspid is an "atrioventricular canal defect" 5,6 depends in turn on the understanding of an "atrioventricular canal malformation". What can be said with certainty is that hearts with straddling tricuspid valve do not possess the most obvious feature of "atrioventricular canals", namely a common atrioventricular junction. As seen in Figure 1, which shows two hearts sectioned in simulated "four-chamber" plane, the heart with straddling and overriding of the tricuspid valve (Fig. 1a) is characterised by presence of separate right and left atrioventricular junctions. In contrast, the "complete atrioventricular canal defect" (Fig. 1b) not only has a common atrioventricular valve, but also a common atrioventricular junction.

This figure also shows the characteristic feature of hearts with straddling of the tension apparatus of the tricuspid valve combined with overriding of its atrioventricular junction, namely malalignment between the muscular ventricular septum and the atrial septum. It is this malalignment that distinguishes the hearts from those without straddling and overriding. It is also because of this malalignment that the atrioventricular conduction axis is unable to take its origin from the regular atrioventricular node found in the triangle of Koch (Fig. 2). Instead, the conduction axis ascends the posterior margin of the muscular ventricular septum and makes contact with an anomalous node situated in the atrial myocardium at the point where the muscular ventricular septum meets the atrioventricular junction. The location of this point of union relative to the overall atrioventricular junction can vary depending on the degree of override of the valve. The site of the anomalous node moves away from the crux 

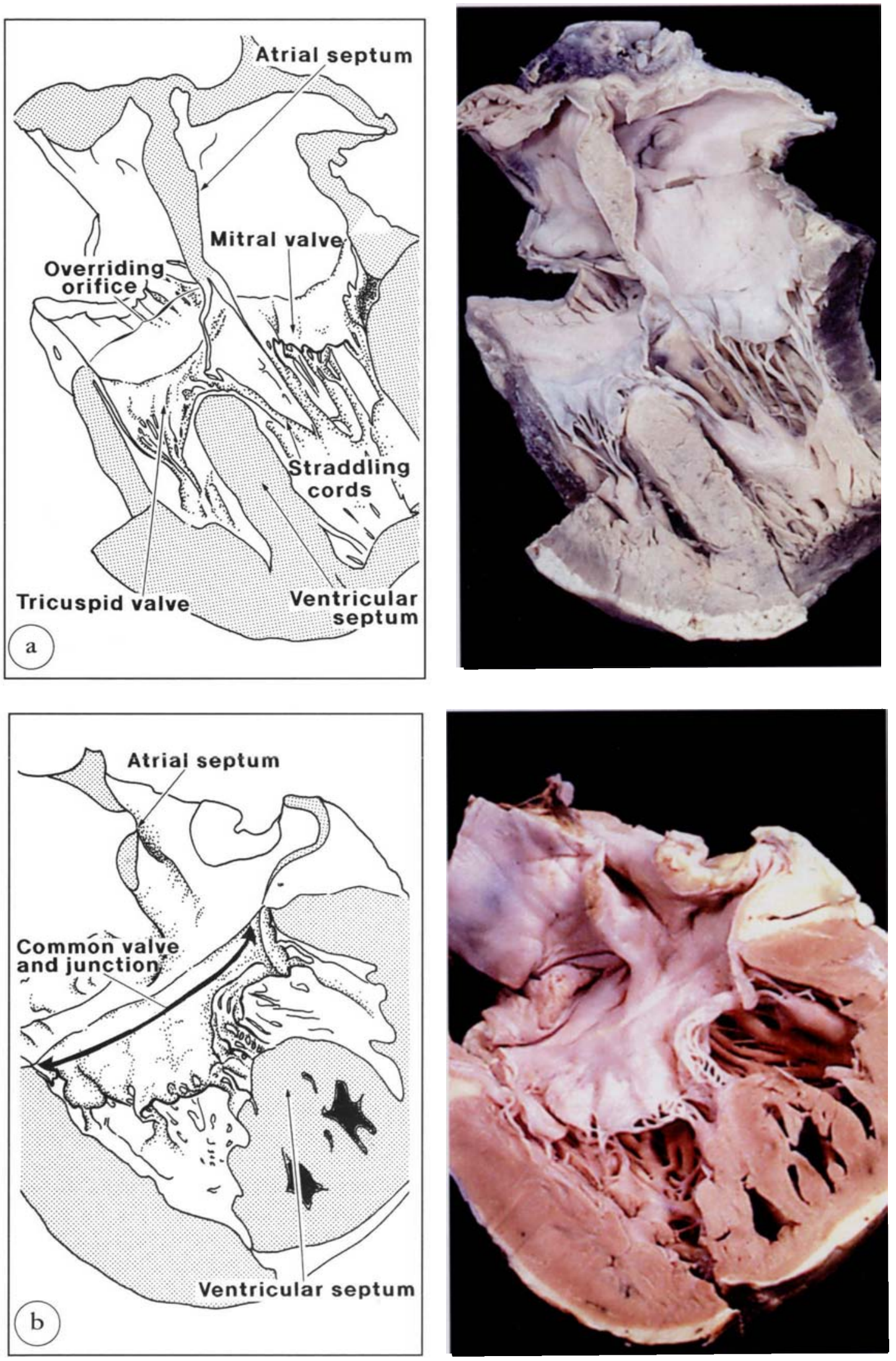

Figure 1.

These simulated "four chamber" sections compare the anatomic arrangements in bearts (a) with straddling and overriding of the tricuspid valve as compared with (b) atrioventricular septal defect with common atrioventricular junction. As can clearly be seen, the specimen with straddling tricuspid valve has separate right and left atrioventricular junctions. 

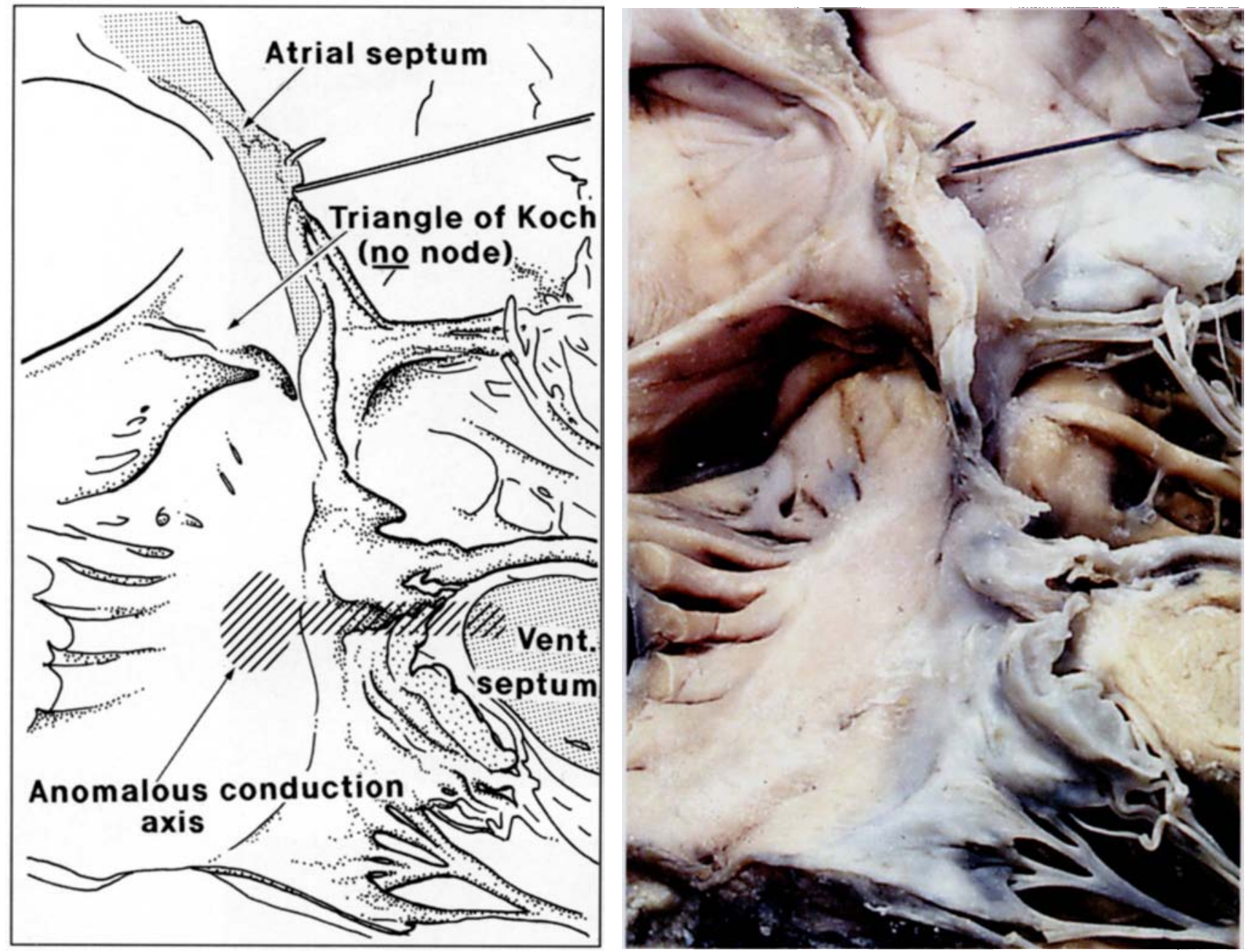

Figure 2.

This view of the posterior atrioventricular junction of the beart illustrated in Figure 1 a shows the malalignment between the atrial and ventricular septal structures which underlies the grossly abnormal disposition of the atrioventricular conduction axis. Note the location of the atrioventricular node.

(Fig. 3) as the atrioventricular connection veers towards the double inlet end of the spectrum known to exist in hearts with straddling and overriding tricuspid valve. ${ }^{7}$ It is unlikely, however, that those hearts at the double inletconnection end of the spectrum will be candidates for the surgical option promoted by Reddy and his colleagues, ${ }^{1}$ since the right ventricle is markedly hypoplastic and rudimentary in such cases (Fig. 4). For those patients suitable for the technique recommended by the San Francisco group, the atrioventricular node is likely to lie at some point along the posterior margin of the right atrioventricular junction (Fig. 2). If the surgeon is to avoid this vulnerable conduction axis, then ideally the entire area of junction between ventricular septum and atrial myocardium must be scrupulously avoided, along with the crest of the ventricular septum. It is clear that the penetrating atrioventricular bundle can be avoided when sutures are placed to the left of the 


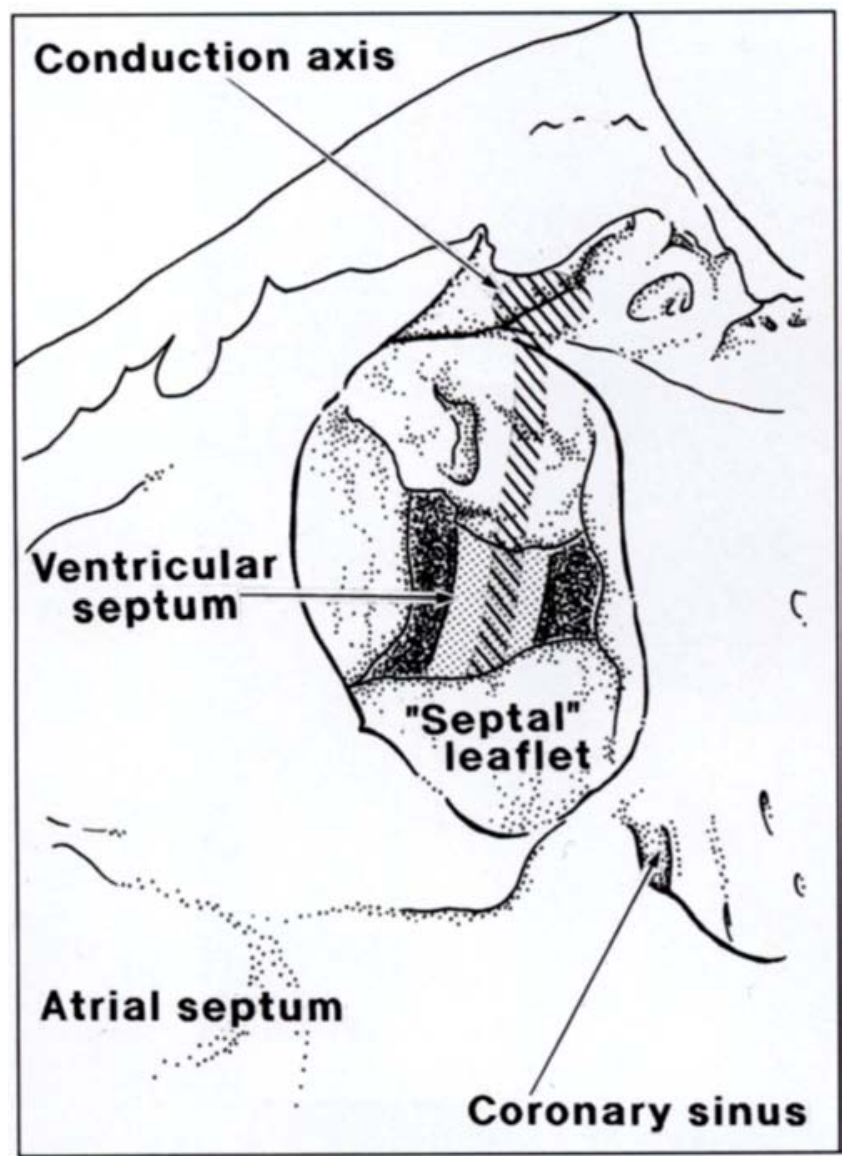

Figure 3.

This shows the right atrioventricular junction of another beart with straddling and overriding of the tricuspid valve viewed as it would be by the surgeon in the operating room, but in which there is double inlet atrioventricular connection (see Figure 4). When compared to the beart shown in Figure 2, with concordant atrioventricular connections, the anomalous atrioventricular node is further away from the crux in the beart with the double inlet connection.

septal crest, as demonstrated by the results of Serraf et al. ${ }^{3}$ It does seem, however, as though the left-sided suture line must, of necessity, come close to the conduction axis at some point in the technique favoured by the Parisians.

In this respect, it seems that Reddy and his colleagues, ${ }^{1}$ as well as Serraf and associates, ${ }^{3}$ are unaware of, or else have forgotten, an alternative means of avoiding the conduction axis when repairing the septal deficiency found in patients with straddling and overriding tricuspid valve. This technique was performed to my knowledge in a single patient by Pedro del Nido, then working at the Children's Hospital of Pittsburgh but now at Boston Children's Hospital. The essence of the technique had previously been described and published by Planché and colleagues from Paris, ${ }^{8}$ although this fact was not appreciated by us when

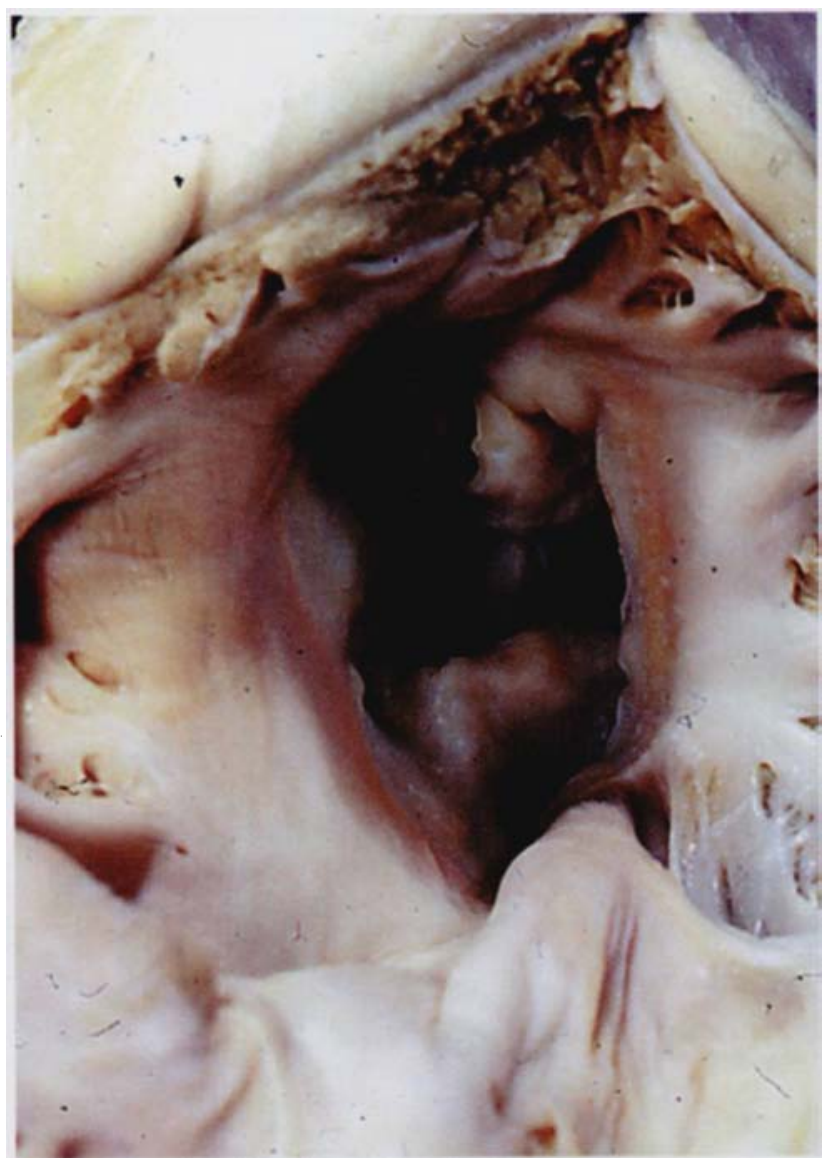

we described del Nido's experience in our account of ventricular septal defects in hearts with complete transposition. ${ }^{9}$ In essence, Planché and his colleagues, ${ }^{8}$ as well as del Nido, used the leaflet tissue of the overriding component of the tricuspid valve to secure the sutures in the areas where the suture line crossed over the atrioventricular conduction axis, placing the other stitches away from the septal crest but on its right ventricular aspect or in the atrial tissues. In this approach, however, the straddling component of the tricuspid valve remained within the left ventricle. When discussing this option with Reddy and his colleagues in the preparation of this note, they raised concern at leaving part of the straddling valve in the left ventricle. An alternative of this approach, nonetheless, would still be applicable using the approach advocated by Reddy $e t a l,{ }^{1}$ and would 

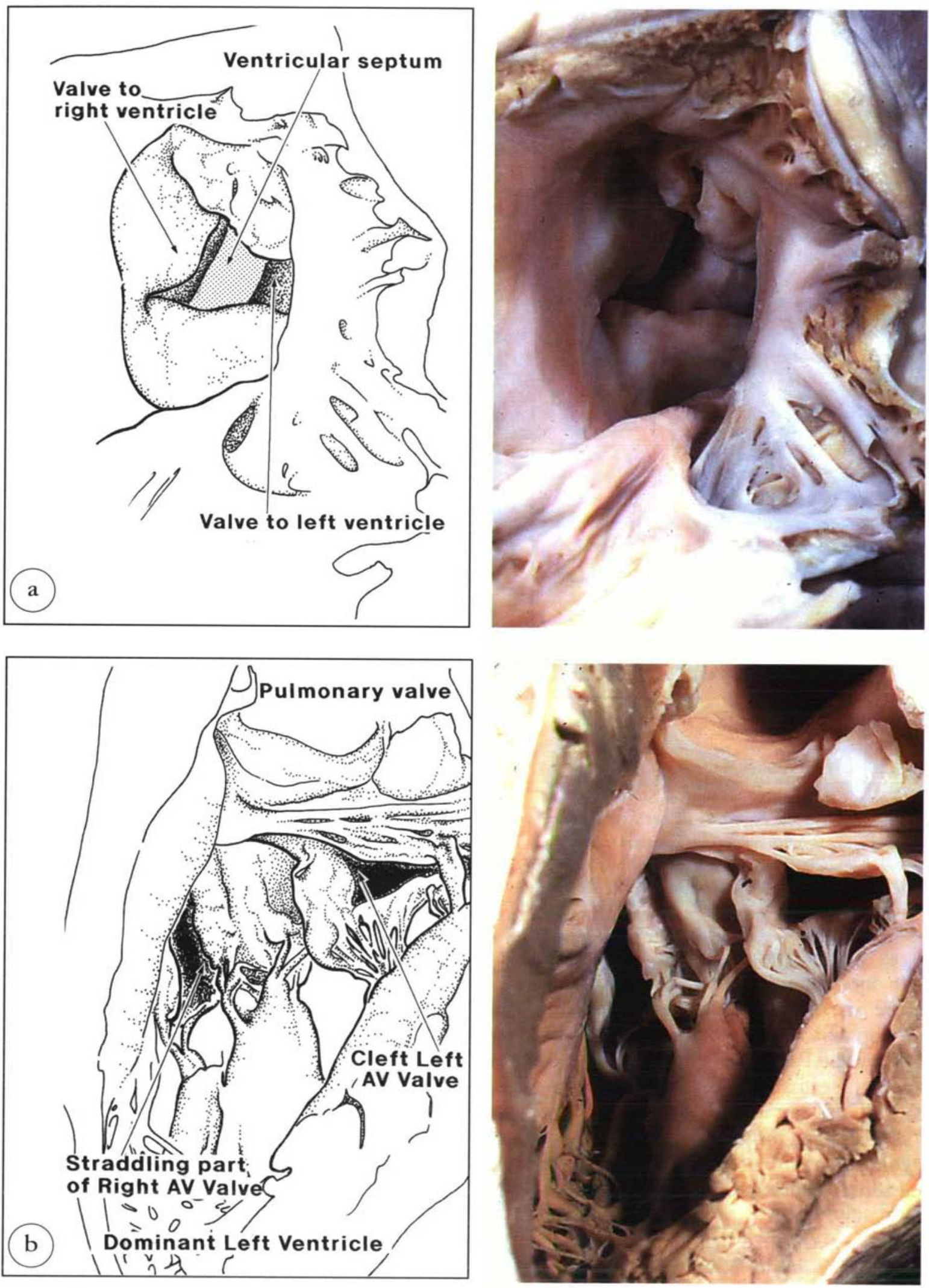

Figure 4.

Further details of the beart with double inlet atrioventricular connection to a dominant left ventricle, but with straddling and overriding of the right atrioventricular valve ( $F i g .4 a$ is seen in surgical orientation). The dominant left ventricle is shown in anatomical orientation in Fig. 4b, and the rudimentary and incomplete right ventricle, again in anatomical orientation, in Fig. $4 c$. (over the page). The ventriculo-arterial connections are discordant. 

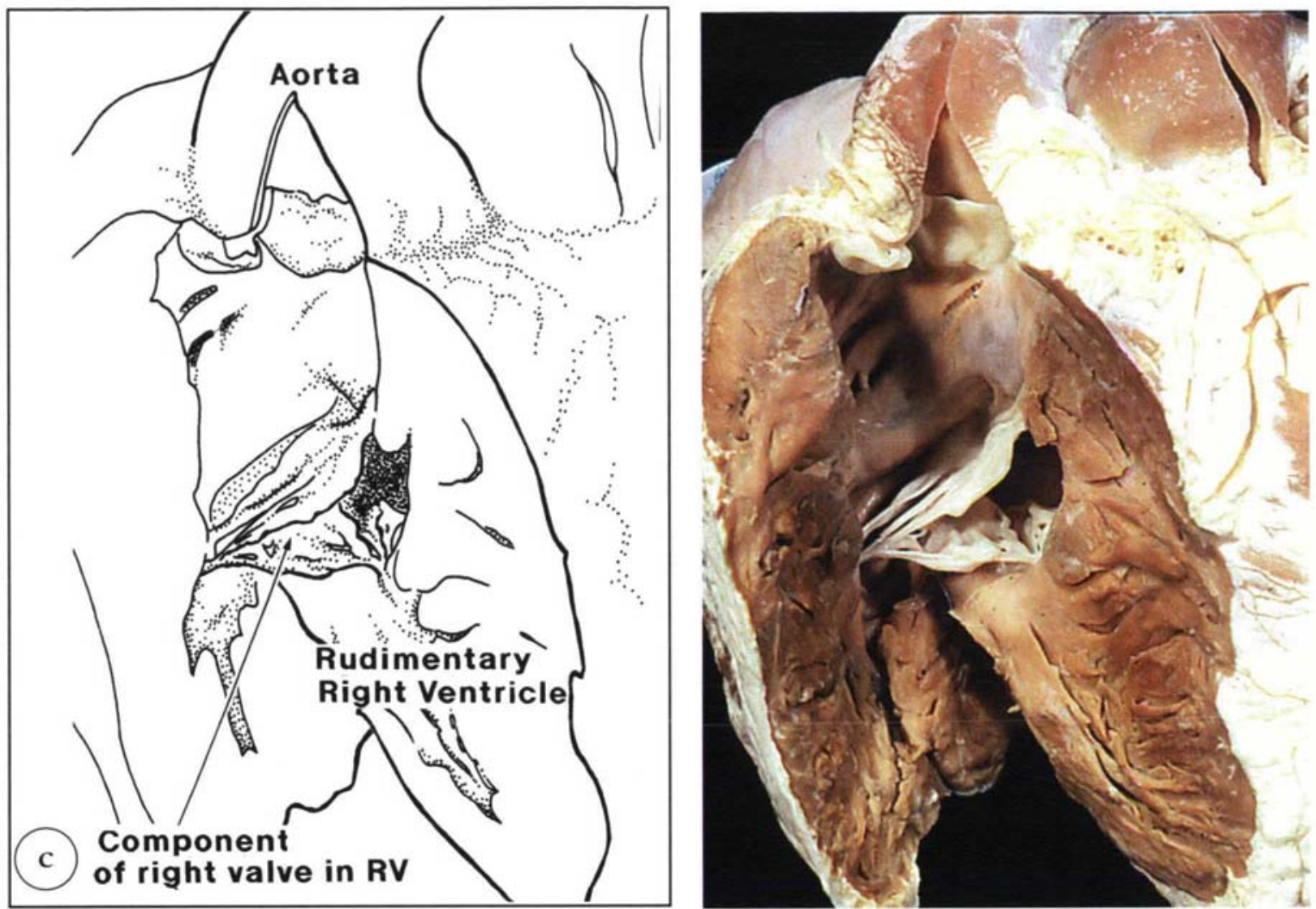

Figure 4. Continued.

The rudimentary and incomplete right ventricle, in anatomical orientation, in Fig. $4 c$. The ventriculo-arterial connections are discordant.

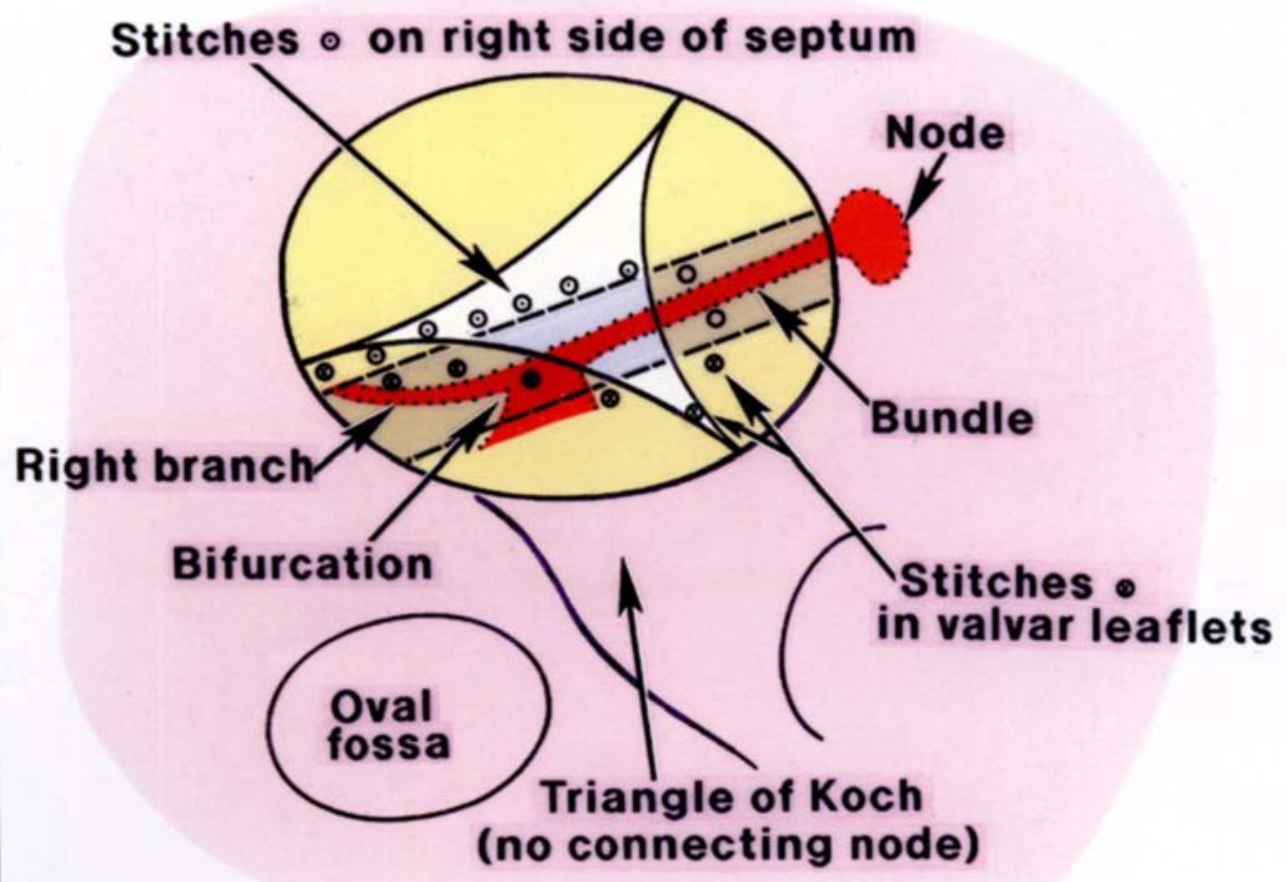

Figure 5.

Diagram showing a possible surgical technique which would avoid the anomalous atrioventricular conduction axis found in bearts with straddling and overriding of the tricuspid valve. The view of the straddling valve is depicted as it would be seen by the surgeon in the operating room (compare with Figs. 3 and $4 a$ ). 
place only the right bundle branch at potential risk during closure of the ventricular communication. Thus, having liberated the straddling leaflet of the valve, it should prove possible to secure stitches on the underside of the leaflet so as to avoid the penetrating component of the conduction axis (Fig. 5). Reddy and his colleagues point out that this still leaves the potential risk of tricuspid regurgitation, but this, to me, seems a lesser evil than surgically induced heart block.

These considerations relative to the location of the atrioventricular conduction axis will certainly become of increasing importance if more surgeons follow the trend established by Serraf, Reddy, and their respective colleagues. ${ }^{1,3}$ It seems sensible to attempt to achieve biventricular rather than univentricular repair, but it also seems that this will be achieved without producing traumatic atrioventricular block only when the precise location of the conduction axis is fully appreciated. As emphasized above, the position of the penetrating atrioventricular bundle reflects the malalignment between the atrial and ventricular septal structures, this being the key to diagnosis of straddling and overriding tricuspid valve. Such malalignment, nonetheless, can co-exist with atrioventricular septal defects and common atrioventricular junction, ${ }^{10}$ so it should also be noted that the major difference between straddling tricuspid valve and atrioventricular canal malformations is the presence of separate as opposed to common atrioventricular junctions.

$$
\begin{array}{r}
\text { Paediatrics } \\
\text { National Heart E Lung Institute } \\
\text { Imperial College of Science, Technology and Medicine } \\
\text { London, United Kingdom }
\end{array}
$$

\section{References}

1. Reddy VM, Liddicoat JR, McElhinney DB, Brook MM, van Son JAM, Hanley FL. Biventricular repair of lesions with straddling tricuspid valves using techniques of cordal translocation and realignment. Cardiol Young.

2. Pacifico AD, Soto B, Bargeron LM. Surgical treatment of straddling tricuspid valve. Circulation 1979;60:655-664.

3. Serraf A, Nakamura T, Lacour-Gayet F, Piot D, Bruniaux J, Touchot A, Sousa-Uva M, Houyel L, PlanchÈ C. Surgical approaches for double-outlet right ventricle or transposition of the great arteries associated with straddling atrioventricular valves. J Thorac Cardiovase Surg 1996;111:527-535.

4. Anderson RH, Wilcox BR. The surgical anatomy of ventricular septal defects associated with overriding valvar orifices. J Card Surg 1993;8:427-439.

5. Rastelli GC, Ongley PA, Titus JL. Ventricular septal defect of atrioventricular canal type with straddling right atrioventricular valve and mitral valve deformity. Circulation 1968;37:816-825.

6. De Vivie R, Van Praagh S, Bein G, Eigster G, Vogt J, Van Praagh R. Transposition of the great arteries with straddling tricuspid valve: teport of two cases with acquired subaortic stenosis after main pulmonary artery banding. J Thorac Cardiovasc Surg 1989;98:205-213.

7. Milo S, Ho SY, Macartney FJ, Wilkinson JL, Becker AE, Wenink ACG, Gitcenberger-de Groor AC, Anderson RH. Straddling and overriding atrioventricular valves: morphology and classification,. Am J Cardiol 1979;44:1122-1134.

8. PlanchÈ C, Fermont L, Bruniaux J, Sidi D, Kachaner J, Binet JP. Straddling de la valve tricuspide travers une communication interventriculaire isolèe. A propos de 4 cas. Arch Mal Coeur 1982;75:905-914

9. Hoyer $\mathrm{MH}$, Zuberbuhler JR, Anderson RH, del Nido P. Morphology of ventricular sepal defects in complete transposition. Surgical implications. J Thorac Cardiovasc Surg 1992;104:1203-1211.

10. Pillai R, Ho SY, Anderson RH, Shinebourne EA, Lincoln C. Malalignment of the interventricular septum and atrioventricular septal defect: its implications concerning conduction tissue disposition. Thorac cardiovasc Surgeon 1984;32:1-3. 